\title{
Lateral Swivel Dislocation of the Hindfoot : A Case Report and Literature Review
}

\author{
${ }^{1}$ Rajesh Kapila, ${ }^{2}$ Partap Singh Verka, ${ }^{3}$ Radhe Sham Garg, ${ }^{4}$ Mannan Ahmed
}

\begin{abstract}
Lateral swivel dislocation, a subtype pattern of dislocations occurring at mid tarsal joint is a rare type of injury. A medially or laterally directed force applied to the forefoot causes dislocation of the talonavicular joint but not subtalar joint. The calcaneum alongwith the remaining foot swivels on the intact interosseous talocalcaneal ligament. The present case report is a more rare lateral swivel type of dislocation of talonavicular joint in a 25-year-old male. The article also presents a comprehensive review of literature and management of such type of injuries of the hindfoot
\end{abstract}

Keywords: Lateral swivel dislocation, Medial swivel dislocation, Subtalar dislocation, Talonavicular dislocation.

How to cite this article: Kapila R, Verka PS, Garg RS, Ahmed M. Lateral Swivel Dislocation of the Hindfoot: A Case Report and Literature Review. J Foot Ankle Surg (Asia-Pacific) 2015;2(1): 41-43.

\section{Source of support: Nil}

Conflict of interest: None

\section{INTRODUCTION}

Isolated dislocation of the talonavicular joint without associated subtalar dislocation or fractures of tarsal bones is a rare occurrence. This region is usually resistant to injury because of the strong ligamentous structures around the midtarsal joint. The strongest ligamentous structures of the midtarsal joint are on the plantar side which is protected by the long and short plantar ligament, bifurcate ligament, and the plantar calcaneonavicular (spring) ligament, which are important as supports for the arch of the foot. ${ }^{1}$

Therefore, dorsal midtarsal dislocation resulting from disruption of these plantar ligaments is less common than other types of midtarsal dislocation. Kennedy et $\mathrm{al}^{2}$ reported a case of navicular fracture dislocation which, by the description of the incident and the reduction maneuver employed, suggests that plantar flexion combined with inversion were the forces required to

\footnotetext{
${ }^{1,2}$ Associate Professor, ${ }^{3}$ Professor, ${ }^{4}$ Postgraduate Student

${ }^{1-4}$ Department of Orthopedics, Government Medical College and Hospital, Amritsar, Punjab, India
}

Corresponding Author: Rajesh Kapila, Associate Professor Department of Orthopedics, 2-B Circular Road, Amritsar Punjab, India, Phone: +91-9814002355, e-mail: kapila.rajesh@ yahoo.com produce the deformity. He also concluded that understanding of the mechanism of injury in these fractures may lead to easier closed reduction and improved outcome.

Main and Jowett described this dislocation type injury occurring at the midtarsal joints with a classification system to help the physician decide the best course of treatment. $^{3}$

A subtype pattern of injury is the swivel dislocation at the talonavicular joint. A medial or lateral directed force to forefoot can result in a swivel dislocation at the talonavicular joint, The following is a description of a patient who sustained an isolated talonavicular joint dislocation and subsequent treatment (lateral swivel type).

\section{CASE REPORT}

A 25-year-old male came to our emergency department with history of motor vehicular accident injuring his right foot. There was diffuse swelling around the ankle and tenderness was felt within the talonavicular joint. Physical examination revealed an obvious deformity with lateral displacement of the fore foot on the head of talus. The skin overlying the talar head on the medial side of the foot was taut. There was no neurovascular deficit. Radiograph (Figs 1 and 2) shows a complex talonavicular dislocation. Closed reduction of the talonavicular dislocation was performed under spinal anesthesia and stabilized by two Percutaneous K-wires using image intensifier (Figs 3 and 4). The postoperative period went uneventful. The patient was immobilized in a plaster of Paris cast for 6 weeks. Gradual physiotherapy was performed to the ankle and foot.

The cast and surgical pins were removed after 6 weeks. Tolerable weight-bearing ambulation began at 8 weeks. The patient made a quick recovery and was allowed to bear full weight at 12 weeks.

He returned to his previous job and no long-term complication at the end of 1 year follow-up was identified. This patient is successfully employed as a manual worker performing normal activities.

\section{DISCUSSION}

Midtarsal joints, including the talonavicular and calcaneocuboid joints, are functionally related to the subtalar and Lisfranc joints. Temporomandibular joint (TNJ) 


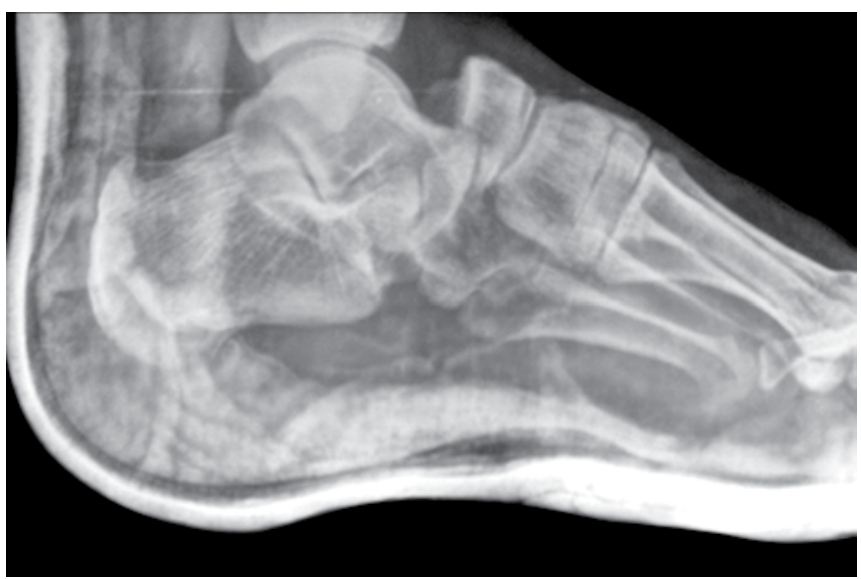

Fig. 1: Talonavicular dislocation (LAT)

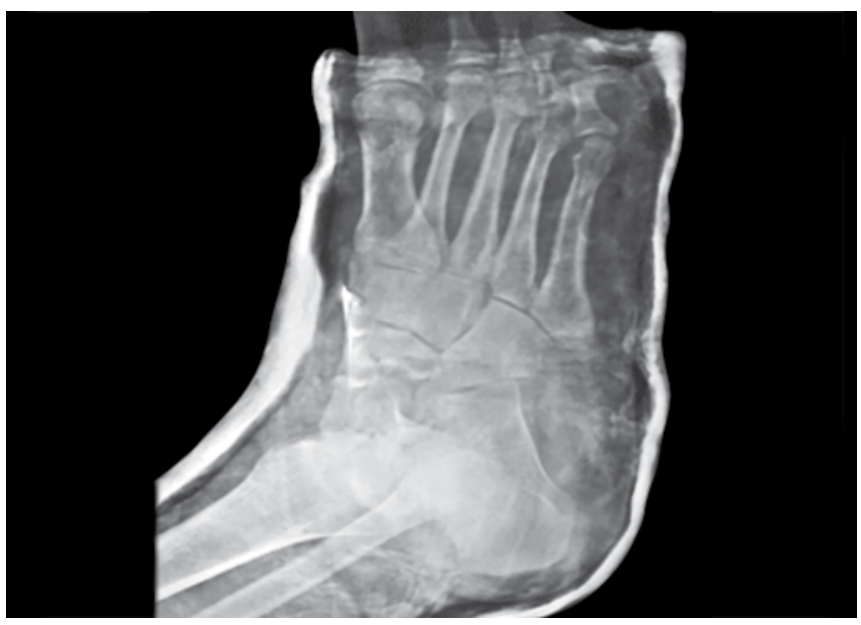

Fig. 3: Postreduction radiograph

dislocation is a rare injury of the foot and ankle with most cases reported occurring after major trauma. Lateral TNJ dislocation, like the one described, are among the more rare types of dislocation occurring at the TNJ after trauma while medial type is more common with a prevalence of $30 \%{ }^{4}$ Main and Jowett classified a series of 71 midtarsal joint injuries into 5 groups according to the direction of the deforming force and the resulting displacement: medial forces, longitudinal forces, lateral forces, plantar forces, and crush injury. ${ }^{3}$ Only two cases of midtarsal dislocation were reported: pure plantar midtarsal dislocation and plantar subtalar dislocation associated with plantar dislocation of the talonavicular joint caused by a plantar force. Cases of isolated midtarsal dislocation in medial, lateral, or plantar directions have been reported. ${ }^{5-8}$ The combination of dorsal dislocation of the navicular from the talus and an associated comminuted fracture of the calcaneus (transcalcaneal, talonavicular dislocation) is an unusual and severe injury and six cases have been described previously. ${ }^{9}$

A swivel dislocation is an uncommon variant of a subtalar dislocation, where a medially or laterally directed force dislocates the talonavicular joint, and subluxates but does not dislocate the subtalar joint. The calcaneus

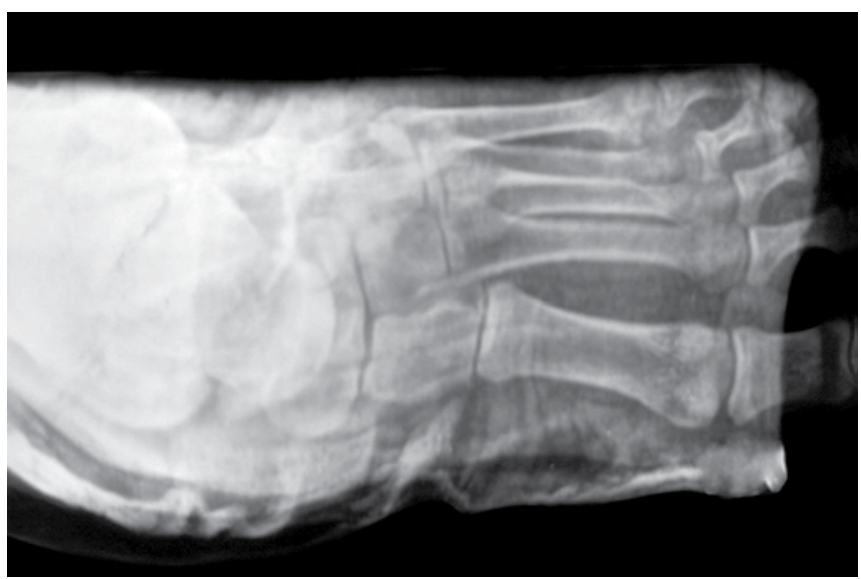

Fig. 2: Talonavicular dislocation (AP)

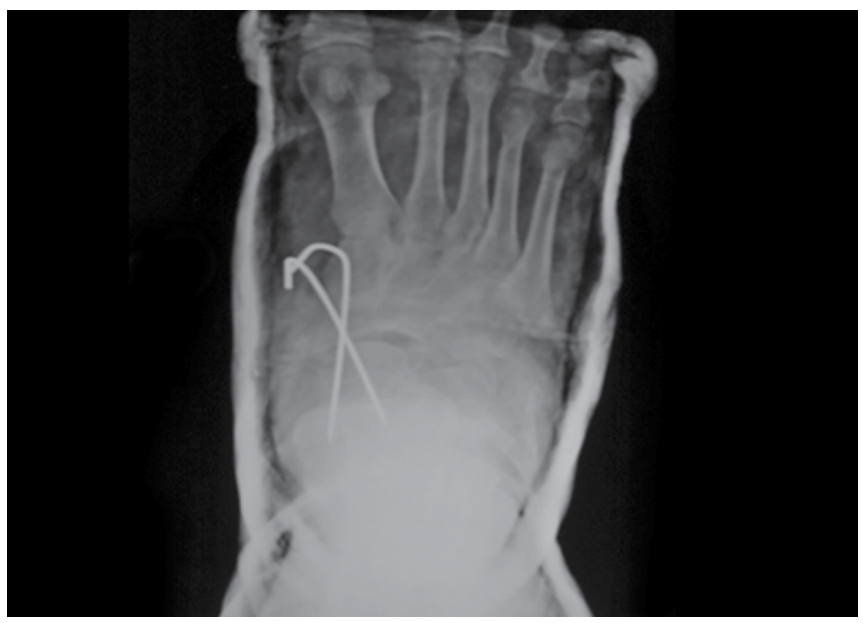

Fig. 4: Postreduction radiograph

rotates or swivels on an intact interosseous talocalcaneal ligament without tearing it. It is important to recognize this injury as early diagnosis and management of such cases is a must for a good outcome..$^{10-13}$ In these complex injuries, an early anatomic reduction and stable fixation can definitely minimize the percentage of long-term impairment. ${ }^{14,15}$

Immediate closed/open reduction and internal fixation gives the best outcome. This improves the stability of the talonavicular joint, which is critical to normal foot biomechanics. Primary fusion of the talonavicular joint after fracture dislocation of the navicular bone is also described (Table 1). ${ }^{15}$

\section{CONCLUSION}

Complex talonavicular dislocations are rare. It represents a severe injury to the plantar ligamentous structures. An early anatomic reduction and stable fixation can minimize the long-term impairment and hence early diagnosis and management is imperative to achieve optimum functional outcome. In our case, anatomical reduction was achieved by closed reduction and stabilized by two percutaneous K-wires to minimize surgical trauma to the soft tissue. The K-wires were kept in place 
Table 1: Brief data on reported cases of swivel dislocation

\begin{tabular}{|c|c|c|}
\hline References & Pattern of injury & Management \\
\hline Keneddy et $\mathrm{al}^{2}$ & $\begin{array}{l}\text { \# dislocation of } \\
\text { talonavicular joint }\end{array}$ & $\begin{array}{l}\text { Closed reduction and } \\
\text { internal fixation }\end{array}$ \\
\hline Pillai et al ${ }^{10}$ & $\begin{array}{l}\text { Lateral swivel } \\
\text { dislocation of } \\
\text { talonavicular joint }\end{array}$ & $\begin{array}{l}\text { Closed reduction and } \\
\text { internal fixation }\end{array}$ \\
\hline Datt et al ${ }^{11}$ & $\begin{array}{l}\text { Medial swivel } \\
\text { dislocation of } \\
\text { talonavicular joint }\end{array}$ & $\begin{array}{l}\text { Open reduction and } \\
\text { internal fixation }\end{array}$ \\
\hline Borman et al ${ }^{12}$ & $\begin{array}{l}\text { Lateral talonavicular } \\
\text { joint dislocation }\end{array}$ & $\begin{array}{l}\text { Closed reduction and } \\
\text { POP cast }\end{array}$ \\
\hline $\begin{array}{l}\text { Powell and } \\
\text { Labella }^{13}\end{array}$ & $\begin{array}{l}\text { Medial swivel } \\
\text { dislocation of } \\
\text { talonavicular joint }\end{array}$ & $\begin{array}{l}\text { Closed reduction and } \\
\text { internal fixation }\end{array}$ \\
\hline
\end{tabular}

for 6 weeks. The reduction appeared satisfactory. After reduction, the patient was kept nonweight bearing and gradually returned to full weight-bearing after 8 weeks. He went back to his manual work with normal activities and occasional pain to the foot. The main aim to present this case is it's rarity and tendency to miss the diagnosis as early diagnosis and treatment are imperative for good functional outcome.

\section{ACKNOWLEDGMENT}

The authors would like to thank Dr Sarika Kapila for providing language help, writing assistance and proof reading of the article.

\section{REFERENCES}

1. McMinn RMH. Last's anatomy: regional and applied. 8th edn. London: Churchill Livingstone 1990;204-217.
2. Kennedy JG, Maher MM, Stephens MM. Fracture dislocation of the tarsal navicular bone: a case report and proposed mechanism of injury. Foot and Ankle Surgery 1999;5(3): 167-170.

3. Main BJ, Jowett RL. Injuries of the midtarsal joint. JBJS 1975 57B:89-97.

4. Miller CM, Winter WG, Bucknell AL, Jonassen EA. Injuries to the midtarsal joint and lesser tarsal bones. J Am Acad Orthop Surg 1998 July-Aug;6(4):249-258.

5. Ruthman JC, Meyn NP. Isolated plantar midtarsal dislocation. Am J Emerg Med 1988 Nov;6(6):599-601.

6. Gaddy B, Perry CR. Chopart dislocation: a case report. J Ortho Trauma 1993;7(4):388-390.

7. Hosking KV, Hoffman EB. Midtarsal dislocations in children. J Paediatr Orthop 1999 Sep-Oct;19(5):592-595.

8. Milgram JW. Chronic subluxation of the midtarsal joint of the foot: a case report. Foot Ankle Int 2002 Mar;23(3):255-259.

9. William RM, Carlo Bellabarba C, Sanders R. Transcalcaneal talonavicular dislocation. J Bone Joint Surg 2002 Apr;84-A(4): 557-561.

10. Pillai A, Chakrabarti D, Hadidi M. Lateral swivel dislocation of the talonavicular joint. Foot Ankle Surg 2006;12(1):39-41.

11. Datt NS, Rao AS, Rao DV. Medial swivel dislocation of talonavicular joint. IJO2009 Jan-Mar;43(1):87-89.

12. Borman WM, Prakken FJ, Pijls BG, Ritchie ED. Lateral talonavicular dislocation after low energy trauma. BMJ case report 2013.

13. Powell E, Labella M. Swivel type dislocation of the talonavicular joint: a case report. The Foot and Ankle 2011 Jun;4(6):3.

14. Richter M, Wippermann B, Krettek C, Schratt HE, Hufner T, Therman H. Fractures and fracture dislocations of the midfoot: occurrence, causes and long-term results. Foot Ankle Int 2001 May;22(5):392-398.

15. Richter M, Thermann H, Huefner T, Schmidt U, Goesling T, Krettek C. Chopart joint fracture-dislocation: initial open reduction provides better outcome than closed reduction. Foot Ankle Int 2004 May;25(5):340-348. 